\title{
Method for Excluding Noise Features in Applying a Learning Machine ${ }^{\dagger}$
}

\author{
By Toshio Nakagawa and Eitaro Masuo \\ Shionogi Research Laboratory, Shionogi Co., Ltd., \\ Fukushima-ku, Osaka, 553
}

Received June 24, 1972

\begin{abstract}
Previous works have demonstrated that a computerized learning machine could be successfully applied to predicting the presence or absence of a certain microbial feature in a microorganism. To achieve the prediction, however, the presence or absence of many other features must be examined beforehand. This paper deals with the method for decreasing the number of characters that must be examined prior to the prediction. In the six instances studied, this number could be decreased from 93 to 11 in the most fortunate case and to 26 in the most unfortunate case, without causing deterioration of the prediction results.
\end{abstract}

Previous works ${ }^{1 \sim 31}$ of this series have demonstrated that a computerized learning machine could be successfully applied to predicting the presence or absence of a certain microbial feature in a microorganism. In predicting four features in an assembly of pseudomonads, the learning machine gave always better results than did experienced microbiologists. ${ }^{3}$ To achieve the prediction, however, the presence or absence of many other features must be examined beforehand. In an example described in part II, ${ }^{2}$ the prediction about whether a microorganism utilizes D-sorbitol or not was made on the examinations of other 93 features such as possession of multitrichous flagella, growth at $4^{\circ} \mathrm{C}$, utilization of D-glucose, etc. Under the circumstances, the practical utility of a learning machine is considered quite limited if any. Everyone desires to get the optimum prediction based upon data as few as possible. This paper deals with the method for decreasing the number of characters that must be examined prior to the prediction-

$\dagger$ Prediction of Microbial Characters by a Computerized Learning Machine, Part IV. See reference 3). but yet without causing deterioration of the results.

\section{PRINCIPLE}

Our learning machine has been developed from the assumption that in a microorganism the presence or absence of a feature (feature in question) was determined by the simple sum of contributions exerted from $n$ other features of the same organism. The feature in question is present if the sum is larger than or equal to a definite value, and absent if it is smaller. In other words, the feature in question is present when $S \geqq 0$ and absent when $S<0$, where

$$
\begin{aligned}
S= & w_{1} x_{1}+w_{2} x_{2}+\cdots+w_{2} x_{3}+\cdots \\
& +w_{n} x_{0}+w_{0} x_{0}
\end{aligned}
$$

$\mathrm{x}_{i}(i=1 \sim n)$ : the number denoting the presence or absence of the $i$ th feature ( 1 for presence, 0 for absence)

$\mathrm{w}_{i}(i=1 \sim n)$ : the weight assigned to the $i$ th feature $w_{0}:$ a constant, $x_{0} \equiv 1$

Provided the $n+1$ weights, wi's $(i=0 \sim n)$, are known, one can calculate $\mathrm{S}$ for any microorganism, for which the $n$ features are known, and thus can predict the presence or absence of the feature in question.

Suppose an assembly of microorganisms, for all of which the presence or absence of the $n+1$ features (the feature in question plus the other $n$ features) is known. If and only if the following four conditions are satisfied, the $n+1$ weights can be determined ac- 


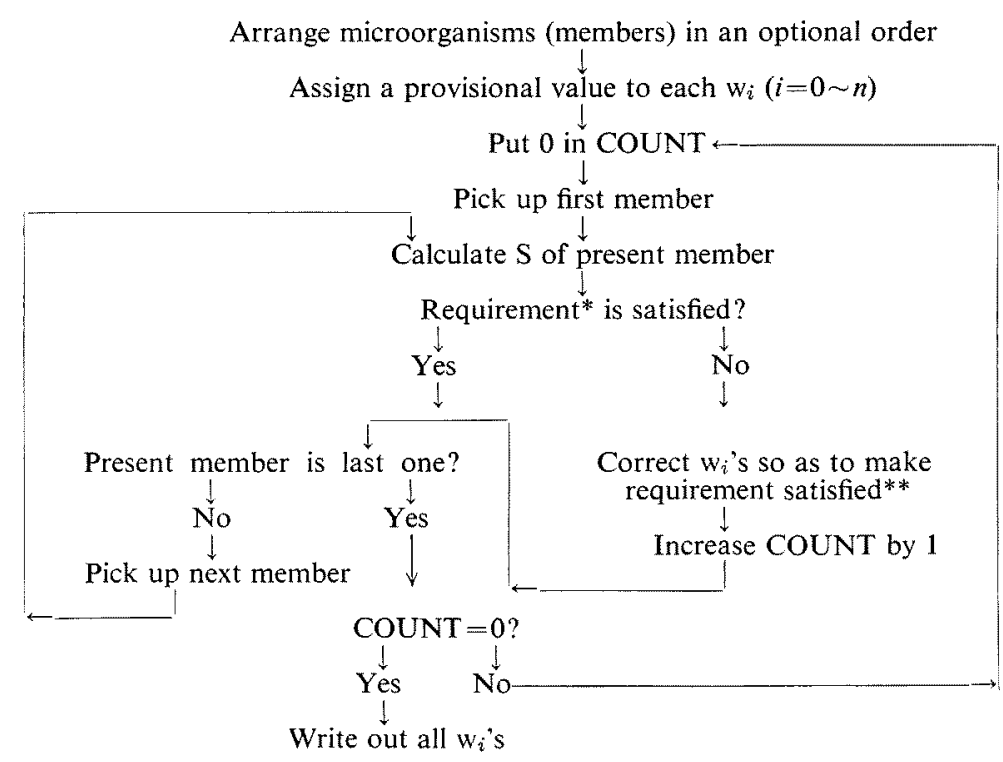

Fig. 1. Flow of Calculation Procedure in a Computer.

* The feature in question is present if $S \geqq 0$, and absent if $S<0$.

** $c f$. Part $I^{1 y}$ for the method of correction.

curately by applying the learning machine to this assembly. 1) The above-mentioned assumption holds rigorously. 2) All features that affect the feature in question are included in the data of features; any feature other than the $n$ features $(i=1 \sim n$ ) has nothing to do with the presence or absence of the feature in question. 3) A quite large number of microorganisms and 4) a wide variety of microorganisms are included in the assembly.

Although these conditions are far from real situations, a set of $w_{i}$-values can be obtained in most cases, with which a majority of or even all of the microorganisms in the assembly show S-values consistent with their features. The percentage of the microorganisms showing consistent $S$ is called Per cent "recognition." 4 " Hereafter, we shall be concerned only with the case of 100 per cent or perfect recognition.

The method for determining $w_{i}$ 's has been detailed in Part I, ${ }^{1 /}$ and therefore, only the flow of calculation procedure in a computer is illustrated in Fig. 1. The first step is the arranging of the microorganisms that constitute the assembly in a discretional order, the second is the assigning of a provisional (not necessarily an identical) value to each $w_{i}$, and the last is the writing out of all $w_{i}$ 's obtained ultimately. In general, different $w_{i}$-values are obtained by different arrangements and/or different sets of weights adopted at the start of calculation. In some of $w_{i}^{\prime}$ 's, even the sign is different; a positive value is obtained in one case while a negative value is obtained in another case.

For $i \geqq 1$, positive $w_{i}$ means that the presence of the $i$ th feature is advantageous for the realization of the feature in question, because $S$ becomes larger when the $i$ th feature is present ( $c f$. Eq. 1). Conversely, negative $w_{i}$ means that the presence of the $i$ th feature is disadvantageous. If the reversal of sign is caused in $w_{i}$ by the change of arrangement or the change of starting weights, the actual direction of the effect exerted by the $i$ th feature cannot be judged (on logical standpoint, biological interrelation between any two features should be indifferent to such artificial changes in computational conditions). The $i$ th feature may be regarded as a feature of ambiguous effect and called a "noise" feature.

It seems rational to exclude noise features* and redetermine the weights of remaining features in order to accomplish the purpose mentioned at Introduction. If the redeterminations with different combinations of the arrangement and the set of starting weights have produced changes of sign in some $w_{i}$ 's of the remaining features, these new noise features are excluded too.

* Excluding some features is synonymous with assigning zeroes to the weights of these features. 
The procedure is repeated until several combinations produce no change of sign in any $w_{i}(i=1 \sim n)$. The prediction is made, of course, based on the features remained ultimately. For finding noise features, Jur $^{53}$ made use of only the change of starting weights in his mass-spectral studies, but simultaneous use of the change of arrangement seems more effective.

The course of excluding noise features may be modified in various ways. The following is an example. Arrange the microorganisms of the assembly in a discretional order and assign a provisional weight, for example $+1,000,000$, to all $w_{i}$ 's. In this example, all $w_{i}$ 's are bestowed an identical starting weight, but this is not a requisite. Computer calculation gives a set of $w_{i}$ 's. A similar set is obtained by assigning another provisional weight, $-1,000,000$. Comparing both sets of $\mathrm{w}_{i}$ "s, one can find out noise features. After excluding the noise features, the same process is applied repeatedly by assigning the same provisional weights, $-1,000,000$ and $-1,000,000$, to the remaining features and $w_{0}$. The stage, where every pair (except $w_{0}$ ) of corresponding weights have the same sign, is attained finally.

A quite similar procedure is applied to the same assembly arranged in another discretional order. In general, the remaining features at the final stage are different between the two cases; different arrangements result in different sets of remaining features. The features that are included in one set but not in the other are regarded as noise features. The features that are commonly included in both sets but have weights of different signs are also regarded as noise features. Thus, both of these features are excluded.

Starting from this stage, the above method is repeated over and over with the same arrangements and the same provisional weights as mentioned above, until the four possible combinations of the two arrangements and the two provisional weights leave an identical series of features, the four weights of every feature having the same sign. This stage is the terminal point of exclusion procedure. Of course, a new exclusion procedure may be commenced with other combinations, although this was not tried in the present work. If imperfect recognition is encountered in the course of excluding noise features, the procedure should be stopped at this stage. Fortunately, it was not encountered in this work.

\section{RESULTS AND DISCUSSION}

In a previous work, 214 strains of pseudo- monads were picked up from a publication of Stanier et al., ${ }^{6}$ ) for which the presence or absence of 94 features was known. These strains were divided into two groups of equal size, A and B. The presence or absence of each of the four features, the production of phenazine compounds and the utilizations of D-sorbitol, of $n$-hexadecane, and of histamine, was predicted - the word predict might be inadequate because the correct answer had already been known - based on the data of the other 93 features. The prediction was made for the 107 members of B-group by using the weights obtained from A-group arranged in two orders called "classification order" and "random order." For the members of A-group, the prediction was made by exchanging the roles of $\mathrm{A}$ and $\mathrm{B}$. In both cases, the weight determination was carried out by assigning a definite positive value to all $\mathrm{w}_{i}$ 's $(i=0 \sim 93)$ at the start of calculation. Except the case of histamine utilization, perfect recognition was attained, and the results of prediction were excellent as represented in Table I. This table shows also the definitions of three measures, PA, EAF, and EPF, by which the prediction results were evaluated ( $c f$. Part $\mathrm{I}^{1)}$ for detailed explanation).

In the present work, the exclusion of noise features was carried out with the same grouping and arrangements as mentioned above but with the two different starting weights of $+1,000,000$ and $-1,000,000$. Table II shows the results obtained. Each row may be read as follows. With regard to (a), the treatment of (b) group gave (c) features which remained ultimately. The weights of the (c) features were determined by arranging (b) group in the (d) order and assigning a starting weight of (e) one million. The presence or absence of (a) was predicted for the members of (f) group, and the results shown in the $7 \sim 9$ th columns were obtained.

Comparison of Tables I and II reveals that 
Table I. Prediction Results Obtained Before Excluding NoISE FeATURES

\begin{tabular}{lllllllll}
\hline \multicolumn{1}{c}{ a } & $\mathrm{b}$ & $\mathrm{c}$ & \multicolumn{1}{c}{$\mathrm{d}$} & $\mathrm{e}$ & $\mathrm{f}$ & PA & EAF & EPF \\
\hline Prod. of & $\mathrm{A}$ & 93 & class. & plus & $\mathrm{B}$ & 0.93 & 1.84 & 1.74 \\
phenazine & $\mathrm{A}$ & 93 & random & plus & $\mathrm{B}$ & 0.93 & 1.84 & 1.74 \\
compounds & $\mathrm{B}$ & 93 & class. & plus & $\mathrm{A}$ & 0.92 & 1.72 & 1.83 \\
& $\mathrm{~B}$ & 93 & random & plus & $\mathrm{A}$ & 0.92 & 1.72 & 1.83 \\
\hline & $\mathrm{A}$ & 93 & class. & plus & $\mathrm{B}$ & 0.95 & 1.89 & 1.90 \\
Util. of & $\mathrm{A}$ & 93 & random & plus & $\mathrm{B}$ & 0.94 & 1.88 & 1.88 \\
D-sorbitol & $\mathrm{B}$ & 93 & class. & plus & $\mathrm{A}$ & 0.92 & 1.82 & 1.81 \\
& $\mathrm{~B}$ & 93 & random & plus & $\mathrm{A}$ & 0.93 & 1.85 & 1.86 \\
\hline & $\mathrm{A}$ & 93 & class. & plus & $\mathrm{B}$ & 0.93 & 1.70 & 1.61 \\
Util. of & $\mathrm{A}$ & 93 & random & plus & $\mathrm{B}$ & 0.91 & 1.68 & 1.53 \\
$n$-hexadecane & $\mathrm{B}$ & 93 & class. & plus & $\mathrm{A}$ & 0.93 & 1.71 & 1.71 \\
& $\mathrm{~B}$ & 93 & random & plus & $\mathrm{A}$ & 0.87 & 1.33 & 1.50 \\
\hline
\end{tabular}

a : Feature to be predicted.

b : Group, on the data of which weights are determined.

$c$ : Number of features other than the feature in question.

d : Order of arrangement of (b) group.

e : Sign of starting weights.

$f$ : Group, for the members of which the prediction is made.

$\mathrm{PA}=(t+w) /(t+u+v+w)$

$\mathrm{EAF}=t /(t+v)+w /(u+w)$

$\mathrm{EPF}=t /(t+u)+w /(v+w)$

where $t, u, v$ and $w$ are the numbers of strains for which the following relation applys.

\begin{tabular}{|c|c|c|c|}
\hline & & \multicolumn{2}{|c|}{ Correct answer } \\
\hline & & Presence & Absence \\
\hline & Presence & $t$ & $" 1$ \\
\hline & Absence & $v$ & $w$ \\
\hline
\end{tabular}

in all cases examined equally good results were obtained before and after the exclusion of noise features. The number of features that must be examined prior to the prediction decreased from 93 to 11 in the most fortunate case and to 26 even in the most unfortunate case. Thus, the purpose mentioned at Introduction has been accomplished.

Biologists may be interested in what kinds of features remained after the exclusion of noise features, wanting to shed light on biological interrelations between various features and the feature in question. As the following example shows, this problem is not so simple as might be supposed. Table III lists up the remained features and the signs of their weights obtained in the case of predicting the utilization of $n$-hexadecane. Eleven and seventeen features remained after processing the data of A-group and B-group, respectively, Only four features are found commonly in these two sets of remained features. One of them, the utilization of L-tryptophan, shows different signs in the two sets. Possibly, this feature has accidentally survived through the course of excluding noise features though it is not intimately related to the utilization of $n$-hexadecane.

In contrast, the production of phenazine compounds shows plus signs in both sets, and moreover, it was found that the utilization of $n$-hexadecane was a feature of plus sign re- 
Table II. Prediction Results Obtained after Excluding NoISE Features

\begin{tabular}{|c|c|c|c|c|c|c|c|c|}
\hline$a$ & $\mathrm{~b}$ & $c$ & $\mathrm{~d}$ & e & $\mathrm{f}$ & PA & EAF & EPF \\
\hline $\begin{array}{l}\text { Prod. of } \\
\text { phenazine } \\
\text { compounds }\end{array}$ & $\begin{array}{l}\text { A } \\
\text { A } \\
\text { A } \\
\text { A } \\
\text { B } \\
\text { B } \\
\text { B } \\
\text { B }\end{array}$ & $\begin{array}{l}21 \\
21 \\
21 \\
21 \\
26 \\
26 \\
26 \\
26\end{array}$ & $\begin{array}{l}\text { class. } \\
\text { class. } \\
\text { random } \\
\text { random } \\
\text { class. } \\
\text { class. } \\
\text { random } \\
\text { random }\end{array}$ & $\begin{array}{l}\text { plus } \\
\text { minus } \\
\text { plus } \\
\text { minus } \\
\text { plus } \\
\text { minus } \\
\text { plus } \\
\text { minus }\end{array}$ & $\begin{array}{l}\text { B } \\
\text { B } \\
\text { B } \\
B \\
\text { A } \\
\text { A } \\
\text { A } \\
\text { A }\end{array}$ & $\begin{array}{l}0.89 \\
0.90 \\
0.90 \\
0.90 \\
0.91 \\
0.92 \\
0.93 \\
0.91\end{array}$ & $\begin{array}{l}1.72 \\
1.74 \\
1.70 \\
1.74 \\
1.70 \\
1.74 \\
1.79 \\
1.75\end{array}$ & $\begin{array}{l}1.64 \\
1.67 \\
1.68 \\
1.67 \\
1.79 \\
1.80 \\
1.86 \\
1.75\end{array}$ \\
\hline $\begin{array}{l}\text { Util. of } \\
\text { D-sorbitol }\end{array}$ & $\begin{array}{l}\text { A } \\
\text { A } \\
\text { A } \\
\text { A } \\
\text { B } \\
\text { B } \\
\text { B } \\
\text { B }\end{array}$ & $\begin{array}{l}20 \\
20 \\
20 \\
20 \\
18 \\
18 \\
18 \\
18\end{array}$ & $\begin{array}{l}\text { class. } \\
\text { class. } \\
\text { random } \\
\text { random } \\
\text { class. } \\
\text { class. } \\
\text { random } \\
\text { random }\end{array}$ & $\begin{array}{l}\text { plus } \\
\text { minus } \\
\text { plus } \\
\text { minus } \\
\text { plus } \\
\text { minus } \\
\text { plus } \\
\text { minus }\end{array}$ & $\begin{array}{l}\text { B } \\
\text { B } \\
\text { B } \\
\text { B } \\
\text { A } \\
\text { A } \\
\text { A } \\
\text { A }\end{array}$ & $\begin{array}{l}0.96 \\
0.94 \\
0.95 \\
0.93 \\
0.94 \\
0.93 \\
0.95 \\
0.93\end{array}$ & $\begin{array}{l}1.92 \\
1.89 \\
1.88 \\
1.86 \\
1.87 \\
1.85 \\
1.87 \\
1.82\end{array}$ & $\begin{array}{l}1.92 \\
1.87 \\
1.92 \\
1.83 \\
1.87 \\
1.82 \\
1.92 \\
1.89\end{array}$ \\
\hline $\begin{array}{l}\text { Util. of } \\
\text { n-hexadecane }\end{array}$ & $\begin{array}{l}\text { A } \\
\text { A } \\
\text { A } \\
\text { A } \\
\text { B } \\
\text { B } \\
\text { B } \\
\text { B }\end{array}$ & $\begin{array}{l}11 \\
11 \\
11 \\
11 \\
17 \\
17 \\
17 \\
17\end{array}$ & $\begin{array}{l}\text { class. } \\
\text { class. } \\
\text { random } \\
\text { random } \\
\text { class. } \\
\text { class. } \\
\text { random } \\
\text { random }\end{array}$ & $\begin{array}{l}\text { plus } \\
\text { minus } \\
\text { plus } \\
\text { minus } \\
\text { plus } \\
\text { minus } \\
\text { plus } \\
\text { minus }\end{array}$ & $\begin{array}{l}\mathrm{B} \\
\mathrm{B} \\
\mathrm{B} \\
\mathrm{B} \\
\mathrm{A} \\
\mathrm{A} \\
\mathrm{A} \\
\mathrm{A}\end{array}$ & $\begin{array}{l}0.94 \\
0.93 \\
0.93 \\
0.93 \\
0.91 \\
0.90 \\
0.91 \\
0.92\end{array}$ & $\begin{array}{l}1.72 \\
1.71 \\
1.78 \\
1.78 \\
1.58 \\
1.47 \\
1.58 \\
1.64\end{array}$ & $\begin{array}{l}1.72 \\
1.66 \\
1.64 \\
1.64 \\
1.65 \\
1.64 \\
1.65 \\
1.68\end{array}$ \\
\hline
\end{tabular}

a : Feature to be predicted.

b: Group, on the data of which weights are determined.

c: Number of features remained ultimately.

$\mathrm{d}$ : Order of arrangement of (b) group.

e : Sign of starting weights.

f : Group, for the members of which the prediction is made.

Table III. Features That Remained Ultimately and The Signs of Their Weights (for Predicting the Utilization of $n$-HEXADECANE)

\begin{tabular}{|c|c|c|c|}
\hline $\begin{array}{l}\text { Obtained by processing A-group } \\
\text { feature }\end{array}$ & Sign & $\begin{array}{l}\text { Obtained by processing B-group } \\
\text { feature }\end{array}$ & Sign \\
\hline $\begin{array}{l}\text { U. of L-tryptophan } \\
\text { P. of phenazine compounds } \\
\text { Po. of multitrichous flagella } \\
\text { U. of } \mathrm{L} \text {-leucine } \\
\text { U. of itaconate } \\
\text { propyleneglycol } \\
n \text {-butanol } \\
o \text {-hydroxy-benzoate } \\
\text { L-isoleucine } \\
\text { butylamine } \\
\alpha \text {-amylamine }\end{array}$ & $\begin{array}{l}+ \\
+ \\
+ \\
- \\
+ \\
+ \\
+ \\
+ \\
+\end{array}$ & $\begin{array}{l}\text { P. of fluorescent pigments } \\
\text { Growth at } 4{ }^{\circ} \\
\text { Growth at } 41^{\circ} \mathrm{C} \\
\text { U. of saccharic acid } \\
\text { adipate } \\
\text { L- }(+) \text {-tartrate } \\
\text { L-lysine } \\
\text { L-citrulline } \\
\text { L-phenylalanine } \\
\text { kynurenate } \\
\text { acetamide } \\
\text { trigonelline } \\
\text { mucate }\end{array}$ & $\begin{array}{l}- \\
+ \\
- \\
- \\
- \\
- \\
+ \\
\pm \\
+ \\
+ \\
+ \\
- \\
- \\
+ \\
+ \\
+ \\
+\end{array}$ \\
\hline
\end{tabular}

U. $=$ Utilization, $\mathrm{P} .=$ Production, Po. $=$ Possession. 
mained commonly in a similar pair of sets in the case of predicting the production of phenazine compounds. This means that between these two features the presence of the one is seemingly advantageous for the realization of the other and vice versa, although it cannot be decided which is the cause or which is the consequence. Or, the two may be sisters born from the same mother. In this connexion, the following findings seem worthy of mention. A large number of hydrocarbonutilizing microorganisms were isolated from soil and waste water of a petroleum refinary. Several of them were found to produce phenazine derivatives such as pyocyanin, ${ }^{7 \sim 9)} 1$ phenazinecarboxylic acid, ${ }^{10 \sim 12}$ 1,6-dihydroxyphenazine (and its 5,10-di-N-oxide), ${ }^{13}$ oxychlororaphine $^{12}$ and iodinin ${ }^{14}$ from various kinds of hydrocarbons as the sole source of carbon. From the current taxonomic point of view, these organisms have been located to genera Pseudomonas, Arthrobacter, Brevibacteritum and Streptomyces. On the other hand, J. C. Senez ${ }^{15}$ reported that pyocyanin might play the role of a hydrogen acceptor having NAD-like affinity in the microbial dehydrogenation of paraffinic hydrocarbon. From these findings, it has been deduced that phenazine pigments were deeply concerned in the hydrocarbon metabolism in some kinds of microorganisms. ${ }^{10,16}$ )

The biological relations of the last two common features, the possession of multitrichous flagella and the utilization of L-leucine, toward the utilization of $n$-hexadecane seem quite puzzling. So far as the authors are aware, no work has ever been published on these relations. Still more puzzling are the effects of features that are included in one set but not in the other- the utilization of L-tryptophan may be regarded as a feature of this category, although it is included in both sets. The authors will not attempt to give a satisfying explanation why equally good results were obtained from quite different sets of features, but only point out that a similar event might be experienced in examinations at schools. A teacher may insist that the mental activity of a student can be judged, at least roughly, from his scores in algebra, German, history and chemistry while another teacher enumerates geometry, French, geography and biology. It seems possible that nearly the same conclusion is attained although quite different sets of curricula were taken into account.

\section{REFERENCES}

1) T. Nakagawa, Agr. Biol. Chem., 35, 1880 (1971).

2) E. Masuo and T. Nakagawa, ibid., 35, 1885 (1971).

3) E. Masuo and T. Nakagawa, ibid., 36, 1433 (1972).

4) P. C. Jurs, B. R. Kowalski and T. L. Isenhour, Anal. Chem., 41, 690 (1969).

5) P. C. Jurs, ibid., 42, 1633 (1970).

6) R. Y. Stanier, N. J. Palleroni and M. Doudoroff, J. Gen. Microbiol., 43, 159 (1966).

7) E. G. H. Lee and C. C. Walden, Appl. Microbiol, 17, 520 (1969).

8) N. V. Pomortseva, Microbiology (USSR), 34, 404 (1965), cited from 10).

9) T. V. Koronelli and L. N. Stepanova, ibid., 37, 372 (1968), cited from 10).

10) T. Higashihara and A. Sato, J. Ferment. Technol., 48, 73 (1970).

11) A. J. Kluyver, J. Bacteriol., 72, 406 (1956).

12) K. Ogata et al., J. Ferment. Technol., 49, 925 (1971).

13) T. Suzuki et al., Agr. Biol. Chem., 35, 92 (1971).

14) I. Tanabe and A. Obayashi, The Memoirs of the Faculty of Agriculture, Kagoshima University, VIII, 373 (1971).

15) J. C. Senez and E. Azoulay, Biochim. Biophys. Acta, 47, 307 (1961).

16) S. Mann, Arch. Mikrobiol., 71, 304 (1970). 